\title{
Erratum to: Early Neonatal Mortality in India, 1990-2006
}

\author{
Chandan Kumar • Prashant Kumar Singh • \\ Rajesh Kumar Rai $\cdot$ Lucky Singh
}

Published online: 20 November 2012

(c) Springer Science+Business Media New York 2012

\section{Erratum to: J Community Health \\ DOI 10.1007/s10900-012-9590-8}

The following errors were inadvertently overlooked in the original publication and they have been corrected with this erratum.

1. "postnatal" should be replaced by "post neonatal" in the 3rd line of the first column under the "Abstract" section, on p. 1.

2. "and for major states in India" should be deleted in the 15-16th line of the first column under the "Abstract" section on p. 1.
The online version of the original article can be found under doi: 10.1007/s10900-012-9590-8.

\section{Kumar $(\bowtie)$}

Department of Humanities and Social Sciences,

Indian Institute of Technology (IIT) Roorkee, Roorkee 246 667,

Uttarakhand, India

e-mail: c.kumar803@gmail.com

P. K. Singh · L. Singh

International Institute for Population Sciences (IIPS),

Govandi Station Road, Deonar, Mumbai 400 088, India

e-mail: prashant_iips@yahoo.co.in

L. Singh

e-mail: lucky_5bhu@yahoo.com

R. K. Rai

Tata Institute of Social Sciences (TISS), V N Purav Marg,

Deonar, Mumbai 400 088, India

e-mail: rajesh.iips28@gmail.com
3. "postnatal" should be replaced by "post neonatal" in the 5th line of the first column under the subheading "Data", on p. 2.

4. "postnatal" should be replaced by "post neonatal" in the 8th line of the first column under the subheading "Trends in ENMR in India: 1970-2008", on p. 4.

5. In Figs. 1, 2 and their caption, "postnatal" should be replaced by "post neonatal".

Revised figures are displayed: 
Fig. 1 Neonatal and post neonatal mortality rate (3-years moving average of the annual estimates), Sample Registration System (SRS), India, 1970-2008

Fig. 2 Contribution of neonatal and post neonatal mortality to overall infant mortality (contributions are estimated calculating proportion of neonatal and post neonatal mortality in infant mortality and using 3-years moving average), Sample Registration System (SRS), India, 1970-2008
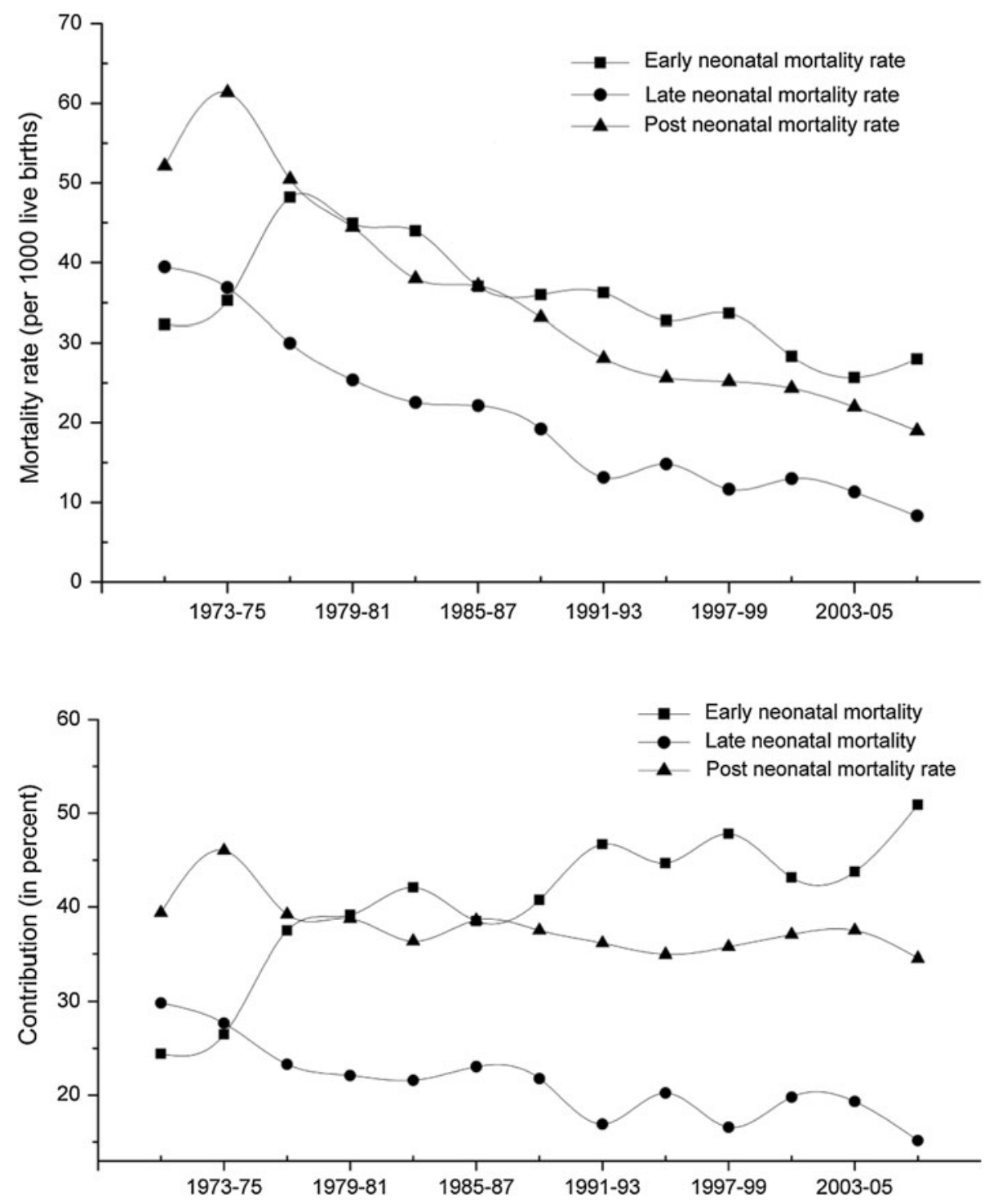